NASA/CR-2005-213426

\title{
Computation of Tone Noise From Supersonic Jet Impinging on Flat Plates
}

Ching Y. Loh

Taitech, Inc., Beavercreek, Ohio 
Since its founding, NASA has been dedicated to the advancement of aeronautics and space science. The NASA Scientific and Technical Information (STI) Program Office plays a key part in helping NASA maintain this important role.

The NASA STI Program Office is operated by Langley Research Center, the Lead Center for NASA's scientific and technical information. The NASA STI Program Office provides access to the NASA STI Database, the largest collection of aeronautical and space science STI in the world. The Program Office is also NASA's institutional mechanism for disseminating the results of its research and development activities. These results are published by NASA in the NASA STI Report Series, which includes the following report types:

- TECHNICAL PUBLICATION. Reports of completed research or a major significant phase of research that present the results of NASA programs and include extensive data or theoretical analysis. Includes compilations of significant scientific and technical data and information deemed to be of continuing reference value. NASA's counterpart of peerreviewed formal professional papers but has less stringent limitations on manuscript length and extent of graphic presentations.

- TECHNICAL MEMORANDUM. Scientific and technical findings that are preliminary or of specialized interest, e.g., quick release reports, working papers, and bibliographies that contain minimal annotation. Does not contain extensive analysis.

- CONTRACTOR REPORT. Scientific and technical findings by NASA-sponsored contractors and grantees.
- CONFERENCE PUBLICATION. Collected papers from scientific and technical conferences, symposia, seminars, or other meetings sponsored or cosponsored by NASA.

- SPECIAL PUBLICATION. Scientific, technical, or historical information from NASA programs, projects, and missions, often concerned with subjects having substantial public interest.

- TECHNICAL TRANSLATION. Englishlanguage translations of foreign scientific and technical material pertinent to NASA's mission.

Specialized services that complement the STI Program Office's diverse offerings include creating custom thesauri, building customized databases, organizing and publishing research results ... even providing videos.

For more information about the NASA STI Program Office, see the following:

- Access the NASA STI Program Home Page at http://www.sti.nasa.gov

- E-mail your question via the Internet to help@sti.nasa.gov

- Fax your question to the NASA Access Help Desk at 301-621-0134

- Telephone the NASA Access Help Desk at 301-621-0390

- Write to:

NASA Access Help Desk

NASA Center for AeroSpace Information 7121 Standard Drive

Hanover, MD 21076 
NASA/CR-2005-213426

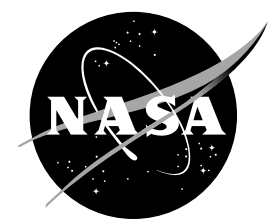

\section{Computation of Tone Noise From Supersonic Jet Impinging on Flat Plates}

Ching Y. Loh

Taitech, Inc., Beavercreek, Ohio

Prepared for the

43rd Aerospace Sciences Meeting and Exhibit

sponsored by the American Institute of Aeronautics and Astronautics

Reno, Nevada, January 10-13, 2005

Prepared under Contract NAS3-03072

National Aeronautics and

Space Administration

Glenn Research Center 


\section{Acknowledgments}

This work received support from the Quiet Aircraft Technology Project Office of NASA Glenn Research Center. Fruitful discussion with Dr. Lennart S. Hultgren and the careful reviewing of the paper by Drs. R.A. Blech and J. Bridges are cordially acknowledged.

This report contains preliminary

findings, subject to revision as analysis proceeds.

Available from

NASA Center for Aerospace Information 7121 Standard Drive

Hanover, MD 21076
National Technical Information Service 5285 Port Royal Road Springfield, VA 22100 


\title{
COMPUTATION OF TONE NOISE FROM SUPERSONIC JET IMPINGING ON FLAT PLATES
}

\author{
Ching Y. Loh \\ Taitech, Inc. \\ Beavercreek, Ohio 45430
}

\begin{abstract}
A supersonic jet impinging normally on a flat plate has both practical importance and theoretical interests. The physical phenomenon is not fully understood yet. Research concentrates either on the hydrodynamics (e.g. lift loss for STOVL) or on the aeroacoustic loading.

In this paper, a finite volume scheme-the space-time conservation element and solution element (CE/SE) method-is employed to numerically study the near-field noise of an underexpanded supersonic jet from a converging nozzle impinging normally on a flat plate. The numerical approach is of the MILES type (monotonically integrated large eddy simulation). The computed results compare favorably with the experimental findings.
\end{abstract}

\section{Introduction}

High speed impinging jets are important to aircraft industry. For vertical landing and short take-off (STOVL) airborned vehicles propelled by jet engines, there are undesirable and adverse effects from the impinging jets. These include up to $60 \%$ lift loss and the acoustic loading and noises generated by a feedback loop between the jet and the ground.

Research on jet impinging normally on a flat plate has unfolded in a broad way. Some researchers concentrate on the hydrodynamics and investigate the lift loss, other researchers focus on the sound produced and the aeroacoustic loading of the impinging jets. There are a vast number of papers published on these topics. For example, after careful observations over the experimental data, Powell [1] pointed out that the small instability waves (vortices) around the jet shear layers and the consequent radial wall jet are responsible for the noise as they interact with the flat plate and produce sound waves. Ho and Nosseir [2] explained the feedback loop in the impinging jets; while Tam and Ahuja [3] put forward another theoretical model for the acoustic feedback loop. In the meantime, experimentalists are conducting various physical experiments in search for the feedback mechanism in different impinging jet situations. Alvi and Iyer [9] studied the impinging jet with lift plate, Krothapalli et al [8] investigate both the jets with convergent nozzle and convergent-divergent (C-D) nozzles. Henderson et al [4 7] performed experiments of sound producingimpinging jets on small and large plates.

Numerical simulations of unsteady impinging jets have also been carried out. Kim and Park [10] used the popular TVD upwind scheme. Sakakibara and Iwamoto [11] also used TVD scheme to study oscillations in impinging jets and the generation of acoustic waves.

In the present paper, a MILES (monotonically integrated large eddy simulation) type scheme is used to investigate the problem of a jet impinging on a flat plate. The MILES approach appears somewhat similar to LES, but there is no explicit filtering since the cell-averaging process is already equivalent to spatial filtering. Due to certain built-in numerical dissipation in a MILES finite volume scheme, the SGS (subgrid scale) model is not needed. The recent space-time conservation element and solution element method (CE/SE) [12-13] is a MILES type finite volume method with generally less numerical dissipation and is adopted for the computation. As demonstrated in previous papers, the $\mathrm{CE} / \mathrm{SE}$ scheme is well suited for aeroacoustics computation $[15,16]$. Because of the CE/SE non-reflecting boundary conditions (NRBC), which are based on the physics of plane wave propagation [14], a smaller near field computational domain can be used in the present numerical simulation and helps to save both memory and CPU time.

The governing equations and the 2-D axisymmetric unstructured Navier-Stokes (N-S) CE/SE scheme used here is briefly reviewed in Section 2. Section 3 illustrates the noise problems of an impinging jet on normal flat plates, both large and small, with the initial and boundary conditions. The numerical results are presented and 
compared to available experimental findings [4 - 7] in Section 4. Concluding remarks are drawn in Section 5.

\section{The Governing Equations and the Unstructured Axisymmetric CE/SE Navier-Stokes Solver}

As our main concern lies in the aeroacoustical behaviors of the impinging jets which remain axisymmetric in the problems under investigation according to the experimental results [4 - 7], it is appropriate to adopt and solve the axisymmetric Navier-Stokes equation system.

\subsection{Conservation Form of the Unsteady Axisymmetric Navier-Stokes Equations}

Consider a dimensionless conservation form of the unsteady axisymmetric Navier-Stokes equations of a perfect gas. Let $\rho, u, v, p$, and $\gamma$ be the density, streamwise velocity component, radial velocity component, static pressure, and constant specific heat ratio, respectively. The axisymmetric Navier-Stokes equations then can be written in the following vector form:

$$
\boldsymbol{U}_{t}+\boldsymbol{F}_{x}+\boldsymbol{G}_{y}=\boldsymbol{Q},
$$

where $x, y \geqslant 0$, and $t$ are the streamwise and radial coordinates and time, respectively. The conservative flow variable vector $\boldsymbol{U}$ and the flux vectors in the streamwise and radial directions, $\boldsymbol{F}$ and $\boldsymbol{G}$, are given by:

$$
\boldsymbol{U}=\left(\begin{array}{c}
U_{1} \\
U_{2} \\
U_{3} \\
U_{4}
\end{array}\right), \quad \boldsymbol{F}=\left(\begin{array}{c}
F_{1} \\
F_{2} \\
F_{3} \\
F_{4}
\end{array}\right), \quad \boldsymbol{G}=\left(\begin{array}{c}
G_{1} \\
G_{2} \\
G_{3} \\
G_{4}
\end{array}\right),
$$

with

$$
\begin{gathered}
U_{1}=\rho, \quad U_{2}=\rho u, \quad U_{3}=\rho v, \\
U_{4}=p /(\gamma-1)+\rho\left(u^{2}+v^{2}\right) / 2 .
\end{gathered}
$$

The flux vectors are further split into inviscid and viscous fluxes:

$$
\mathbf{F}=\mathbf{F}_{\mathbf{i}}-\mathbf{F}_{\mathbf{v}}, \mathbf{G}=\mathbf{G}_{\mathbf{i}}-\mathbf{G}_{\mathbf{v}}
$$

where the subscripts $i$ and $v$ denote 'inviscid' and 'viscous' respectively. Details of these terms can be found in e.g. $[17,16]$.

The right hand source term $Q$ is the same as in the axisymmetric Euler equations $[17,16]$ :

$$
\boldsymbol{Q}=\left(\begin{array}{l}
Q_{1} \\
Q_{2} \\
Q_{3} \\
Q_{4}
\end{array}\right)
$$

where

$$
Q_{1}=-U_{3} / y, \quad Q_{2}=-U_{2} U_{3} / U_{1} y
$$

$$
Q_{3}=-U_{3}^{2} / U_{1} y, \quad Q_{4}=-G_{4} / y .
$$

By considering $(x, y, t)$ as coordinates of a threedimensional Euclidean space, $E_{3}$, and using Gauss' divergence theorem, it follows that Eq. (1) is equivalent to the following integral conservation law:

$$
\oint_{S(V)} \boldsymbol{H}_{m} \cdot \mathrm{d} \mathbf{S}=\int_{V} Q_{m} \mathrm{~d} V, \quad m=1,2,3,4,
$$

where $S(V)$ denotes the surface around a volume $V$ in $E_{3}$ and $\boldsymbol{H}_{m}=\left(F_{m}, G_{m}, U_{m}\right)$.

\subsection{Treatment of the Source Term}

The treatment is identical to the one used in [17] and is briefly reiterated here. Since the source term $Q$ itself is a function of the unknown $\boldsymbol{U}$, a local iterative procedure is needed to determine $\boldsymbol{U}$. The discretized integral equation (2) reduces to the form

$$
\boldsymbol{U}-\boldsymbol{Q}(U) \Delta t=\boldsymbol{U}_{H},
$$

where $\boldsymbol{U}_{H}$ is the local homogeneous solution $(\boldsymbol{Q}=0$ locally). Note that $\boldsymbol{U}_{H}$ only depends on the solution at the previous time step, i.e., $\boldsymbol{U}_{H}$ is obtained using explicit formulas. A Newton iterative procedure to determine $\boldsymbol{U}$ is then

$$
\boldsymbol{U}^{(i+1)}=\boldsymbol{U}^{(i)}-\left(\frac{\partial \Phi}{\partial \boldsymbol{U}}\right)^{-1}\left[\boldsymbol{\Phi}\left(\boldsymbol{U}^{(i)}\right)-\boldsymbol{U}_{H}\right],
$$

where $i$ is the iteration number and

$$
\boldsymbol{\Phi}(\boldsymbol{U})=\boldsymbol{U}-\boldsymbol{Q}(\boldsymbol{U}) \Delta t .
$$

Normally, $\boldsymbol{U}$ at the previous time step is a good initial guess $\boldsymbol{U}^{(0)}$ and the procedure takes about 2-3 iterations to converge. The Jacobian matrix is given by

$$
\frac{\partial \Phi}{\partial \boldsymbol{U}}=\left(\begin{array}{cccc}
1 & 0 & \frac{\Delta t}{y} & 0 \\
-\frac{U_{2} U_{3} \Delta t}{U_{1}^{2} y} & 1+\frac{U_{3} \Delta t}{U_{1} y} & \frac{U_{2} \Delta t}{U_{1} y} & 0 \\
-\frac{U_{3}^{2} \Delta t}{U_{1}^{2} y} & 0 & 1+\frac{U_{3} \Delta t}{U_{1} y} & 0 \\
A_{1} & A_{2} & A_{3} & 1+\frac{\gamma U_{3} \Delta t}{2 U_{1} y}
\end{array}\right)
$$

where

$$
\begin{gathered}
A_{1}=-\frac{U_{3} \Delta t}{U_{1} y}\left[\gamma U_{4}-\frac{(\gamma-1)\left(U_{2}^{2}+U_{3}^{2}\right)}{U_{1}}\right], \\
A_{2}=-(\gamma-1) \frac{U_{2} U_{3} \Delta t}{U_{1}^{2} y}, \\
A_{3}=\frac{\Delta t}{y}\left[-\frac{\gamma-1}{2} \frac{U_{2}^{2}+3 U_{3}^{2}}{U_{1}^{2}}+\frac{\gamma U_{4}}{U_{1}}\right] .
\end{gathered}
$$

The inverse of the Jacobian, i.e., $\left(\frac{\partial \Phi}{\partial \boldsymbol{U}}\right)^{-1}$ can easily be derived analytically for this particular case, thus, leading to a savings in CPU time. 


\subsection{Review of the CE/SE Numerical Scheme}

The space-time conservation element and solution element(CE/SE) method is a recently developed finite volume method, with second order accuracy in both space and time. Here, CE (conservation element) stands for a control volume or cell, while SE (solution element) stands for the cell interfaces. Despite its nominal second order accuray, the scheme may offer high resolution, lower dissipation and dispersion errors $[12,13]$. As a result of the following advantageous features, the CE/SE scheme is chosen as the numerical tool for computation:

1. conservation in both space and time, the integral equations of conservation laws are literally solved;

2. only a compact cell stencil is needed, (hence both the conservative variables $\mathbf{U}$ and their gradients $\mathbf{U}_{\mathbf{x}}, \mathbf{U}_{\mathbf{y}}$ are unknowns);

3. careful and accurate surface flux calculation;

4. truly multi-dimensional, simple but effective nonreflecting boundary conditions (NRBC);

5. effortless implementation of computation, no numerical fix or parameter choice is needed;

6. the scheme is of MILES type (monotonically integrated large eddy simulation), the finite volume cell-averaging plays a role of filter, while the van Albada limiter plays a role similar to a SGS model.

7. naturally adapted to unstructured grid, robust enough to cover a wide spectrum of compressible flow: from weak linear acoustic waves to strong, discontinuous waves (shocks), appropriate for both CFD ( computational fluid dynamics) and CAA (computational aeroacoustics).

With an unstructured grid, the CE/SE scheme is easily adapted to complicated geometries. More details about the unstructured CE/SE method can be found in [13]. The weighted $a-\epsilon \mathrm{CE} / \mathrm{SE}$ scheme is used here.

\section{The Impinging Jet Problem}

When a supersonic underexpanded jet impinges normally on a flat plate, some shock cell structure is formed, and near the flat plate a stand-off or plate shock appears. As the jet flow approaches the plate, it is turned into a radial wall jet(Fig. 1). Then it is believed that the instability waves or vorticities generated in the jet shear layer interact with the plate and produce acoustic waves. As these acoustic waves propagate upstream to the nozzle exit where the shear layer receptivity is the highest, they trigger a new cycle of instability waves and thus complete the feedback loop.

The impinging jet problems are set up following the configuration in Henderson's experiment [4 - 7]. The

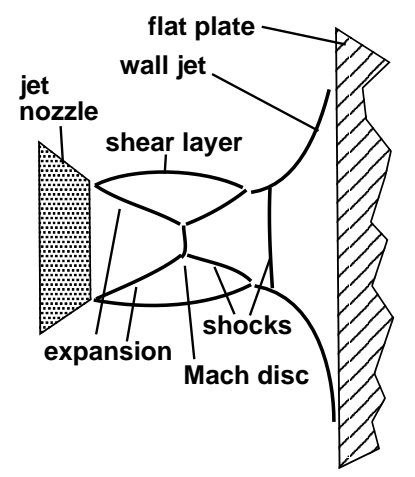

Figure 1: A sketch of the impinging jet problem.

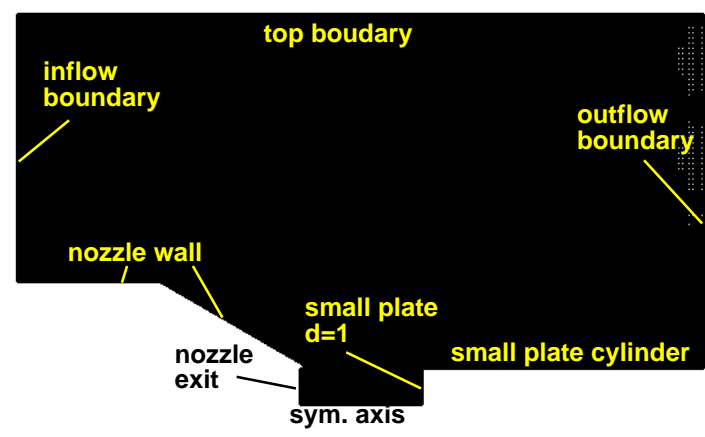

Figure 2: Typical computational domain for impinging jet nozzle exit.

ambient density $\rho_{0}$, the ambient speed of sound and the diameter of the nozzle exit are chosen as the scales for density, velocity and length. The computational domain includes a near field of the flow. Figure 2 and 3 show typical computational domains for the current impinging jet problems. As the flow is considered as axisymmetric, the two-dimensional computational domains are half of the axial section of the corresponding 3-D domains. In the case of a small plate with diameter $\mathrm{d}$, equal to $\mathrm{D}$, the domain ranges from $x=-3$ to $x=7$ (sponge/buffer zone not included) in the stream direction; while in the case of a large plate, the domain ranges from $x=-2$ to $x=3.4$ or $x=4.5$ with the nozzle exit always located at $x=2$. The axial location of the end flat plate depends on the ratio of $h / D$. Here $h / D=1.4$ and 2.5. Typically, there about 35,000 to 40,000 triangulated cells in the domain. They are formed by dividing a rectangle cell diagonally into four pieces, as shown in Fig. 2 and 3. In the area critical to aeroacoustic feedback loop around the jet core, the grid sizes are $\Delta x=0.05$ and $\Delta r=0.025$ to ensure enough resolution.

\subsection{Initial Conditions}

Initially, the flow of the entire domain is set at the ambient flow conditions, i.e., (using nondimensional variables) 

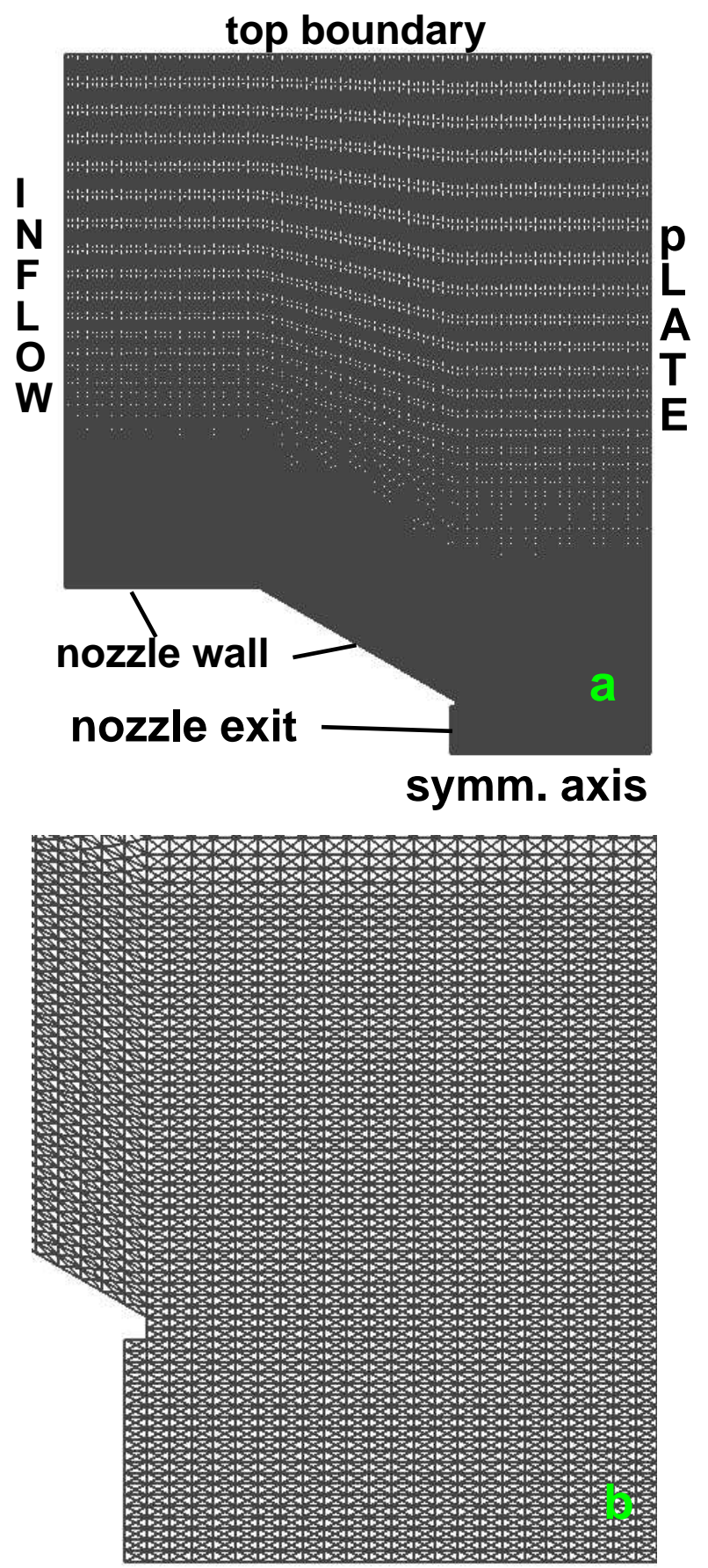

Figure 3: a: Typical computational domain and grid (with buffer/sponge zone at the top) for a large end plate; b: an enlargement of the grid around the nozzle exit.

$$
\rho_{a}=1, \quad p_{a}=\frac{1}{\gamma}, \quad u_{a}=0, \quad v_{a}=0 .
$$

here, the subscript $a$ stands for 'ambient'.

\subsection{Boundary Conditions}

At the inlet boundary, the conservative flow variables and their spatial derivatives are specified to be those of the ambient flow, except at the nozzle exit, where an elevated pressure is imposed, i.e., the jet is underexpanded, as in the experiments. As the jet flow at the nozzle exit is choked $\left(M_{e}=1\right)$, and the ratio of stagnation (plenum) pressure $p_{0}$ to the ambient pressure $p_{a}$, $N P R=p_{0} / p_{a}=4.03$, by using the ideal gas isentropic relations, it follows that

$$
\frac{p_{0}}{p_{e}}=\left[\frac{\gamma+1}{2}\right]^{\frac{\gamma}{\gamma-1}}=1.893, \quad \text { or } \quad p_{e}=2.1289 p_{a}
$$

Other nondimensional flow variables at the nozzle exit, with $M_{e}=1$ (choked flow with convergent nozzle), are given by

$$
\begin{gathered}
\rho_{e}=\frac{\gamma(\gamma+1) p_{e}}{2 T_{r}}, \\
u_{e}=\left(\frac{2 T_{r}}{\gamma+1}\right)^{1 / 2}, \quad v_{e}=0,
\end{gathered}
$$

where $T_{r}$ is the reservoir (plenum) temperature. We will also follow the experimental cold-flow condition where the reservoir temperature equals the ambient one, i.e., $T_{r}=1$.

At the symmetry axis, i.e., $y=0$, a simple reflective boundary condition is applied. At the top boundary, the Type I CE/SE non-reflecting boundary conditions as described in the next subsection are imposed. The no-slip boundary condition is applied on the nozzle walls and the end plate.

\subsection{Non-Reflecting Boundary Conditions}

As the spatial derivatives of the conservative flow variables are also considered as unknowns, the CE/SE scheme supports a simple but robust non-reflecting boundary condition (NRBC). Details and proof of the new NRBC can be found in [14]. The following is the Type I NRBC employed in this paper.

For a grid node $(j, n)$ lying at the outer radius of the domain the non-reflective boundary condition (Type I) requires that

$$
\left(\boldsymbol{U}_{x}\right)_{j}^{n}=\left(\boldsymbol{U}_{y}\right)_{j}^{n}=0,
$$

while $U_{j}^{n}$ is kept fixed at the initial steady boundary value. At the downstream outflow boundary, the nonreflective boundary condition (Type II) requires that

$$
\left(\boldsymbol{U}_{x}\right)_{j}^{n}=0,
$$



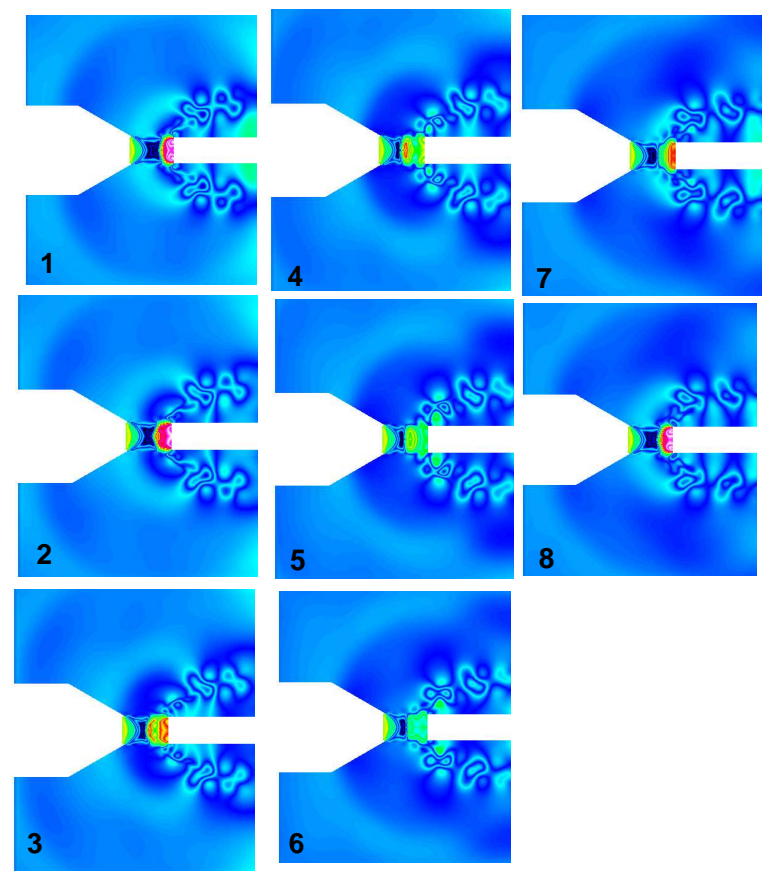

Figure 4: Plots 1-8: isobars at different time steps in a cycle, showing oscillations of the shock cell, the plate shock, the radiating acoustic waves and the vortices in the wakes in the small plate case.

while $\boldsymbol{U}_{j}^{n}$ and $\left(\boldsymbol{U}_{y}\right)_{j}^{n}$ are now defined by simple extrapolation from the nearest interior node $j^{\prime}$, i.e.,

$$
\boldsymbol{U}_{j}^{n}=\boldsymbol{U}_{j^{\prime}}^{n-1} \quad\left(\boldsymbol{U}_{y}\right)_{j}^{n}=\left(\boldsymbol{U}_{y}\right)_{j^{\prime}}^{n-1} .
$$

As will be observed later, these NRBCs, when combined with the buffer zone, are robust enough to allow a clean near field computation without disturbing or distorting the flow and acoustic fields.

\section{Numerical Results}

As sketched in Fig. 1, when the jet hits the plate, a radial wall jet is formed along with the instability waves. It is believed that when the instability waves interact with the flat plate and generate acoustic waves that propagate upstream via either the jet shear layer or the jet exterior to the nozzle lip and complete the acoustic feedback loop. In this section, the cases of a small plate and a large plate are considered.

\subsection{Jet Impinging on a Small Plate}

Consider a supersonic underexpanded jet from a convergent nozzle. With a small plate of diameter $d$ placed downstream of the jet nozzle exit, the free jet becomes an impinging jet. The small plate is indeed a solid circular cylinder aligned with the nozzle axis. According to the experiment [5], the small plate has a diameter $\mathrm{d}=\mathrm{D}$ and the distance between the jet nozzle exit to the plate is

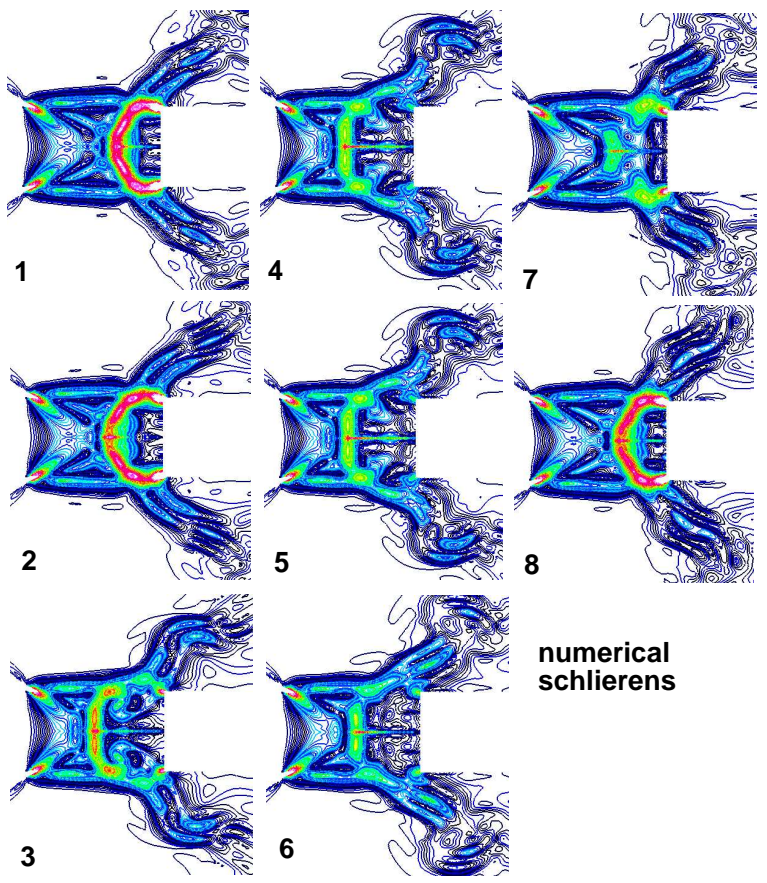

Figure 5: Plots 1-8: numerical schlierens showing the cyclic movements of the shock cell and plate shock.

$\mathrm{h}=1.65 \mathrm{D}$, where $\mathrm{D}=2.54 \mathrm{~cm}$ is the jet diameter at nozzle exit. The ratio of stagnation pressure to ambient pressure is set at NPR $=4.03$.

4.1.1 The unsteady oscillating flow Figure 4 illustrates the isobars at different time steps in about a cycle, after 1.47 million steps were already run. It is clearly displayed that the toroidal instability vortical waves grow along the jet shear layer upstream of the plate cylinder, and then interact with the bow shock (plate shock) and more importantly with the edge of the plate cylinder. The vortices are deflected and convect downstream with the flow, while the interaction generates acoustic waves that propagate in the field. As the waves reach the nozzle exit lip, where the receptivity is the highest, another cycle of vortices is triggered and the feedback loop is thus completed. In our view, the situation is somewhat similar to the feedback loop of a high speed cavity noise problem, although the situation may be different for a larger plate diameter.

Figure 5 is the numerical schlierens showing the cyclic movements of the shock-cell, in particular, the shock cell shocks and the plate shock. The strong oscillation of the shocks indicates strong, nonlinear waves in the near field.

4.1.2 Acoustic waves and frequency Figure 6 shows the same isobar plots as in Fig. 4 but with pressure limited between $0.6-0.8$ (non-dimensional val- 


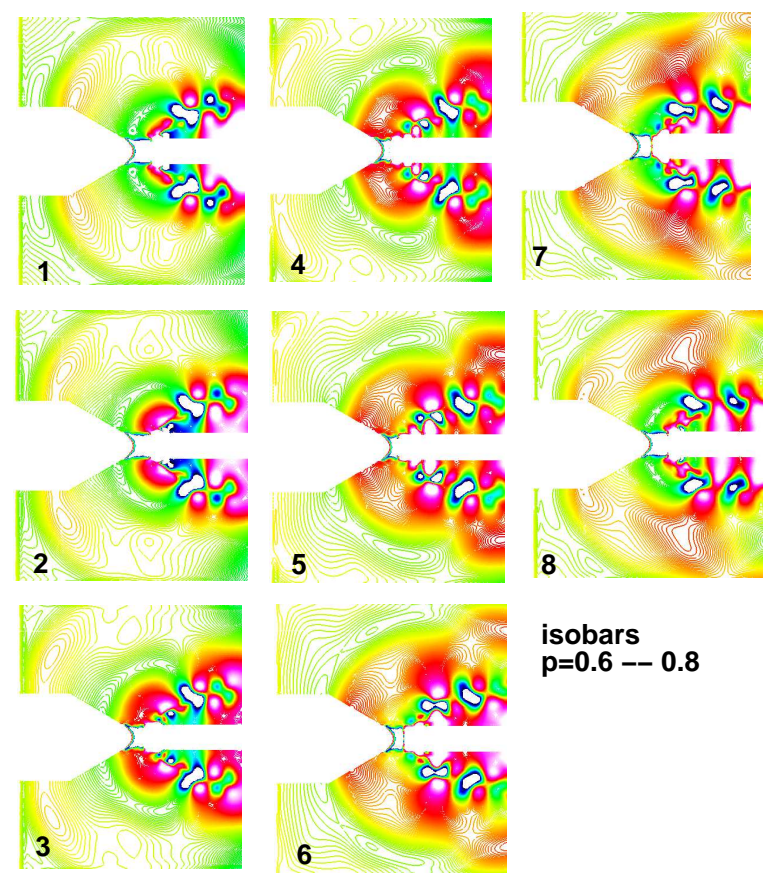

Figure 6: Plots 1-8: isobar contours with pressure limited within 0.6-0.8, showing acoustic waves generation and propagation.

ues). The generation and propagation of acoustic waves are clearly observed. The pressure history is recorded for a location $(-1.5,2)$ upstream of the nozzle exit. Fourier analysis is then performed to obtain the spectrum. Figure 7 is the computed SPL (sound pressure level) plot at this location. It is observed that the waves are strong (over $150 \mathrm{~dB}$ ), as expected. The fundamental frequency is about $3,300 \mathrm{~Hz}$ with ample harmonics. This compares well with a similar but not exactly the same case in [4], where $h=1.65 \mathrm{D}$ but NPR $=4.40$ instead of 4.03 , which has a fundamental frequency of $3,570 \mathrm{~Hz}$.

\subsection{Jet Impinging on a Large Plate $(h / D=1.4)$}

For the case of a jet impinging on a large normal flat plate, the plate diameter is $d=10 \mathrm{D}$ (note that there is a buffer zone beyond $\mathrm{d}=10 \mathrm{D}$ in the computational domain), and NPR=4.03. Two spacings between the nozzle exit and the plate, namely, $\mathrm{h}=1.4 \mathrm{D}$ and $\mathrm{h}=2.5 \mathrm{D}$, are considered. Figure 8 is the numerical schlierens at different time steps, the shock cell and the plate shock (stand-off shock) are clearly displayed but their hydrodynamic movements are much weaker than the previous case. Figure 9 illustrates snapshots of a similar experimental schlierens [6] for qualitative comparison.

With the pressure values limited in a narrow range of $0.71-0.72$, Fig. 10 demonstrates how the acoustic waves are generated and propagate in a series of snapshots. Figure 11 is a snapshot of isobars, giving particular details of

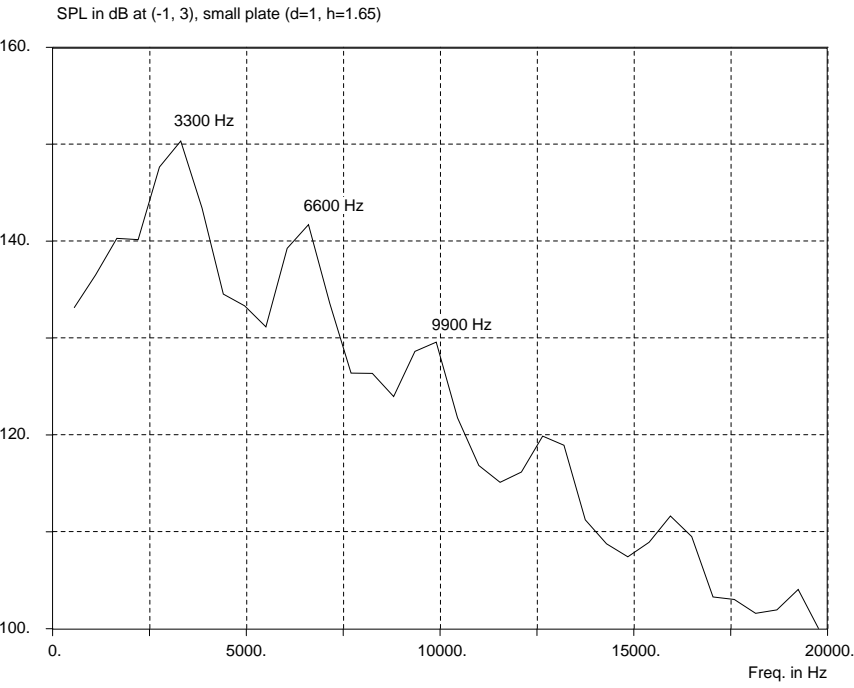

Figure 7: SPL at $(-1,2)$ (upstream of nozzle exit) for a small plate of $\mathrm{d}=\mathrm{D}$, binwidth $=80 \mathrm{~Hz}$.

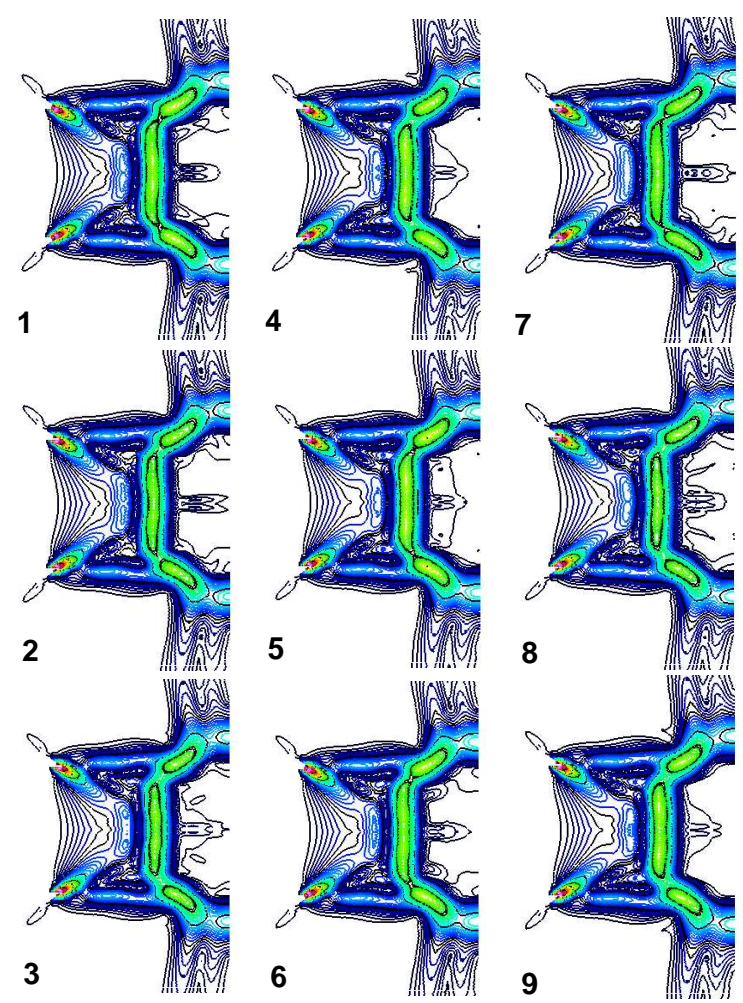

Figure 8: Plots 1-9: numerical schlierens for large flat plate case, the cyclic hydrodynamic movements of the shock cell and plate shock are weaker than the previous case of small plate. 

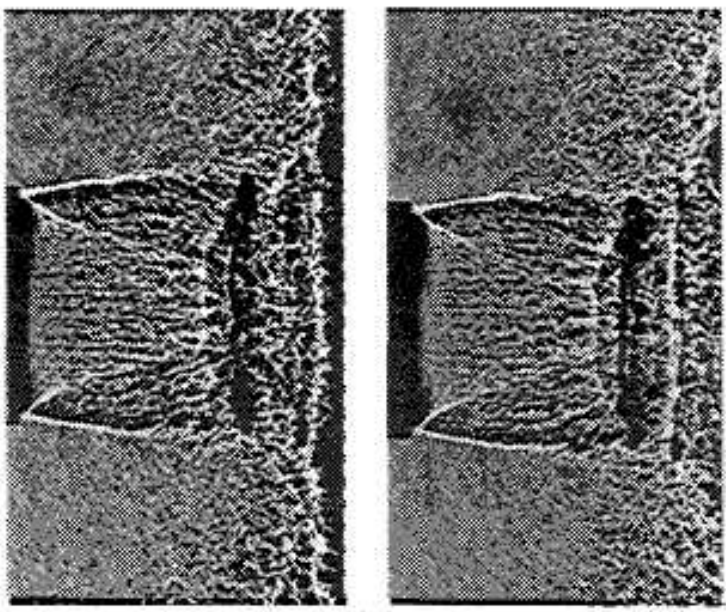

Figure 9: Snapshots of experimental schlierens for a similar case with $\mathrm{h} / \mathrm{D}=1.4, \mathrm{NPR}=4.06$ (from [6 - 7])

the vortices along the jet and wall jet shear layers, which are believed to be responsible for the noise generation. Figure 12 shows the vortices around the jet and wall jet in experiment, for qualitative comparison with Fig. 11.

The computed SPL at a point upstream of the nozzle exit is shown in Fig. 13. The spectrum is calculated after 2.7 million time steps has run. The computed tone SPL is slightly greater than $110 \mathrm{~dB}$, which means the waves are much weaker than in the case with a small plate. Also, there are ample harmonics, as described in Henderson's work [6].

\subsection{Jet Impinging on a Large Plate $(h / D=2.5)$}

As the physical behaviors for this large plate case with large spacing between nozzle exit and the plate is similar to the previous case, only the SPL at a point upstream of the nozzle exit is presented in Fig. 14.

\subsection{Comparison to Experimental Acoustic Data}

In addition to the above qualitative comparison of the structures of shock cell or vortical instability waves around the wall jet, comparisons of the computed frequencies in both small and large plate cases with similar experimental data show that they are similar. The comparisons are still somewhat qualitative, since we can only find similar experimental data under slightly different operating conditions. The experimental data are from Henderson and Powell [4] (figure 11 in their paper) and Alvi and Iyer [9] (Fig. 22 in their paper). Table 1 shows the comparisons. As the data are measured visually from the charts, a small error is inevitable. From Table 1, it is confirmed that the computed frequencies are in the right range.

Although the sound producing mechanism in the im-

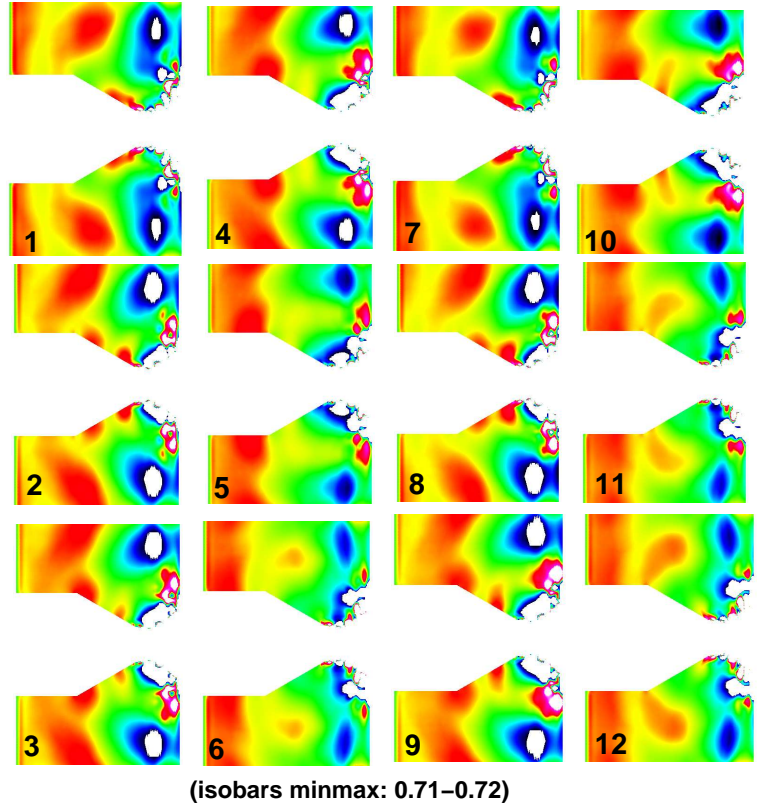

Figure 10: Wave generation in an impinging jet with a large plate, $\mathrm{h} / \mathrm{D}=1.4$. Isobar values are limited within 0.71-0.72 in order the weaker acoustic waves can be displayed.

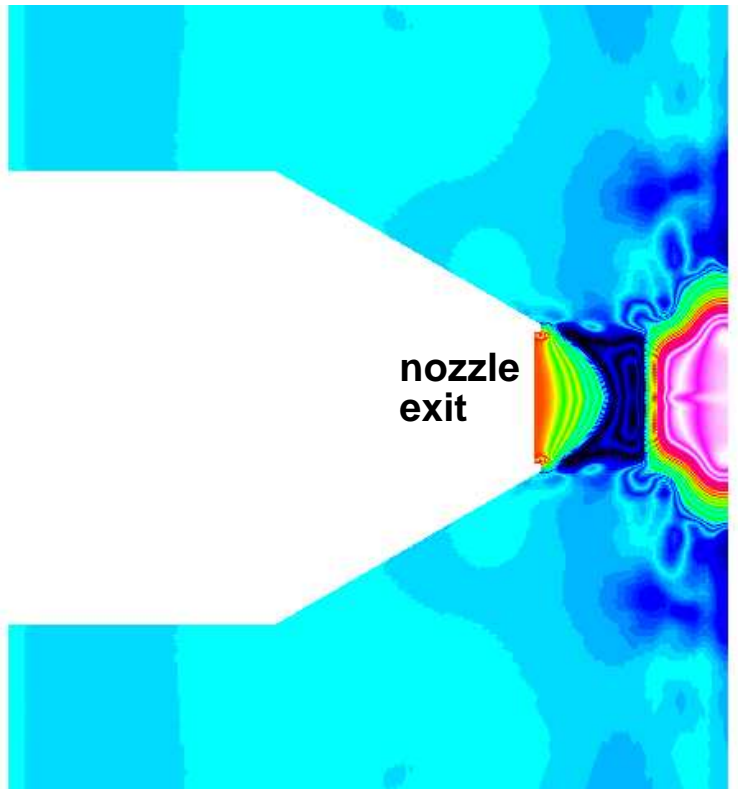

Figure 11: A snapshot of isobars showing presence of various vortical eddies around the jet core and wall jet 


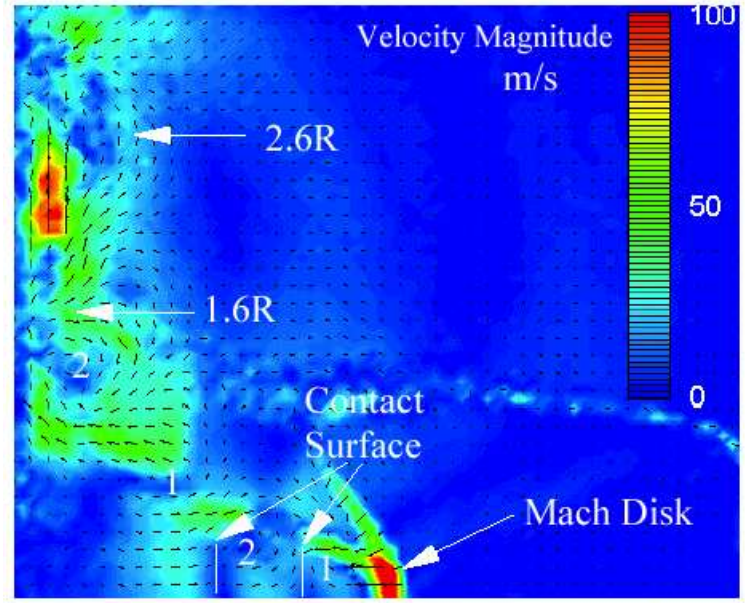

Figure 12: Experimental subtracted velocity vectors around the jet core and wall jet[6], showing the complicated vortical eddies there. (note that the flow is in opposite direction in the experiment)

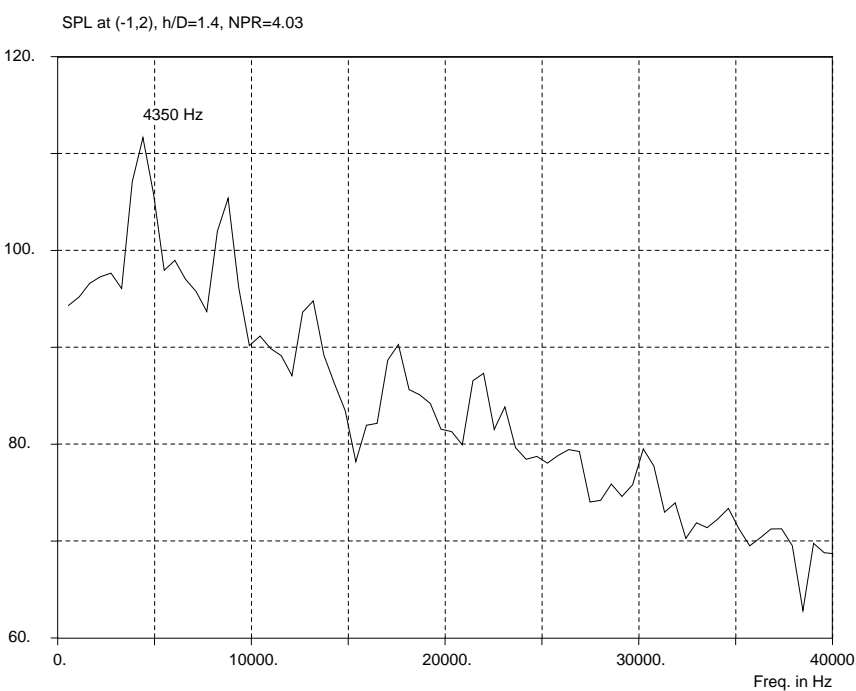

Figure 13: SPL at $(-1,2)$ (upstream of nozzle exit) for a large plate, $\mathrm{h} / \mathrm{D}=1.4, \mathrm{NPR}=4.03$, binwidth $=80 \mathrm{~Hz}$.

Table 1: comparison of tone frequencies

\begin{tabular}{|c|c|c|c|}
\hline & computed & $\begin{array}{l}\text { Henderson }[4 \\
\text { (exp.) }\end{array}$ & $\begin{array}{c}\text { Alvi [9] } \\
\text { (exp.) }\end{array}$ \\
\hline $\begin{array}{c}\text { small plate } \\
\qquad \mathrm{d}=\mathrm{D}\end{array}$ & $\begin{array}{c}3.3 \mathrm{kHz} \\
\mathrm{NPR}=4.03\end{array}$ & $\begin{array}{c}3.57 \mathrm{kHz} \\
\mathrm{NPR}=4.40 \\
\mathrm{~S} 4 \text { mode }\end{array}$ & - \\
\hline $\begin{array}{c}\text { large plate } \\
\text { (case 1) }\end{array}$ & $\begin{array}{c}4.4 \mathrm{kHz} \\
\mathrm{h}=1.4 \mathrm{D} \\
\mathrm{NPR}=4.03\end{array}$ & $\begin{array}{c}5.1 \mathrm{~Hz} \\
\mathrm{~h}=1.4 \mathrm{D} \\
\mathrm{NPR}=4.40\end{array}$ & $\begin{array}{c}4.2 \mathrm{kHz} \\
\mathrm{h}=1.6 \mathrm{D} \\
\mathrm{NPR}=3.70 \\
\text { w. lift plate }\end{array}$ \\
\hline $\begin{array}{c}\text { large plate } \\
\text { (case 2) }\end{array}$ & $\begin{array}{c}5.43 \mathrm{kHz} \\
\mathrm{NPR}=4.03 \\
\mathrm{~h} / \mathrm{D}=2.5\end{array}$ & $\begin{array}{c}5.38 \mathrm{kHz} \\
\mathrm{NPR}=4.40 \\
\mathrm{~h} / \mathrm{D}=2.5\end{array}$ & - \\
\hline
\end{tabular}

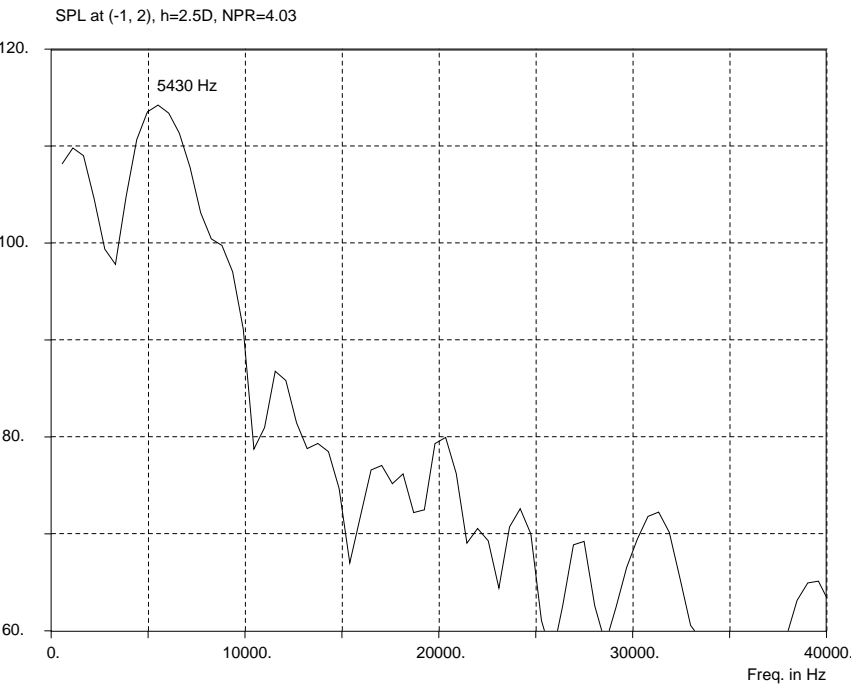

Figure 14: SPL at $(-1,2)$ (upstream of nozzle exit) for a large plate, $\mathrm{h} / \mathrm{D}=2.5, \mathrm{NPR}=4.03$, binwidth $=80 \mathrm{~Hz}$.

pinging jet is not fully understood, the numerical work may shed some light on how the acoustic wave is generated near a flat plate. Figure 15 shows a typical instantaneous pressure field plus a velocity vector field on top of it (Here $h=2.5 \mathrm{D}$ with a large plate). Near the stagnation point of the plate, a high pressure bubble with diameter of about $1-1.5 \mathrm{D}$ is formed. Outside the bubble, the pressure quickly reduces to the ambient level. In the feedback loop, instability waves (vortices) are shed from the nozzle lip and grow in strength and size along the jet shear layer. When the vortices pass through the tips of the shock in the jet core and the plate shock, and enter the high pressure stagnation bubble (Fig. 15), the entire flow experiences severe changes in terms of all the flow variables $u, v, p$ and $\rho$. The vortices will be deformed and distorted, and an acoustic wave is thus generated. For example, when a vortex turns $90^{\circ}$ inside the high pressure bubble and exits the bubble along with the radial wall jet stream, it interacts with high gradient compression wave or shock, and generates an acoustic wave. Outside the stagnation bubble, the acoustic wave appears to originate from a location near the plate but right outside of the stagnation bubble as sketched in Fig. 15. This also explains the experimental observation in [6] that the sound waves occur at a location of the plate 1.3D from the centerline (Fig. 12), because this location lies just outside the high pressure bubble.

\section{Concluding Remarks}

In this paper, we attempt to numerically simulate the important phenomena of a supersonic underexpanded jet impinging normally on flat plates, with emphasis on their aeroacoustic behaviors. 


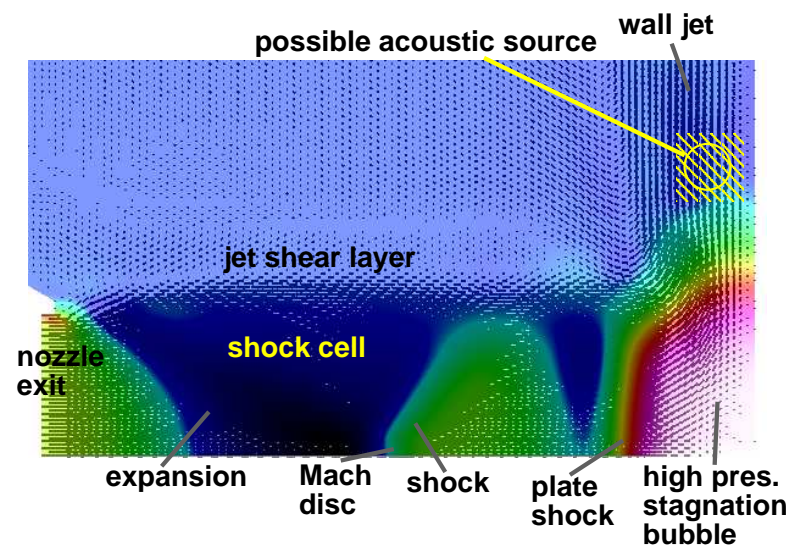

Figure 15: Instantaneous pressure field and velocity vector field, $\mathrm{h}=2.5 \mathrm{D}$.

The numerical method used is based on the recently developed CE/SE scheme solving the axisymmetric Navier-Stokes equations. As the scheme possesses low dissipation while being capable of capturing shocks, the numerical results compare favorably to both hydrodynamic and acoustic experimental findings [4 - 9] even given the two-dimensional axisymmetric approximation. However, for jet impinging on a large plate, the sound genration mechanism is still not fully understood and we have put forward an explanation for the mechanism based on the numerical results. More investigations are needed in the impinging jet problem to further validate the numerical work.

\section{References}

[1] A. Powell, "The sound-producing oscillations of round underexpanded jets impinging on normal plates", J. Acoust. Soc. Am. vol. 83 (2), pp. 515$533,1988$.

[2] C-M. Ho and N. Nosseir, "Dynamics of an impinging jet. Part I. The feedback phenomenon", J. Fluid Mech. vol. 105, pp. 119-142, 1981.

[3] C.K.W. Tam andK.K. Ahuja, "Theoretical model of discrete tone generation by impinging jets", J. Fluid Mech. vol. 214, pp. 67-87, 1990.

[4] B. Henderson and A. Powell, "Experiments Concerning Tones Produced by an Axisymmetric Choked Jet Impinging on Flat Plates", J. Sound Vib. vol. 169(2), pp. 307-326, 1993.

[5] B. Henderson and A. Powell, "Sound Production Mechanisms of the Axisymmetric Choke Jet Impinging on Small Plates: the Production of Primary Tones”, J. Acoust. Soc. Am. vol. 99 (1), pp. 1996.
[6] B. Henderson, J. Bridges and M. Wernet, "An Investigation of the Flow Structure of Tone Producing Supersonic Impinging Jets", AIAA Paper 20022529, 2002.

[7] B. Henderson, "An Experimental Investigation into the Sound Producing Characteristics of Supersonic Impinging Jets", AIAA Paper 2001-2145, 2001.

[8] A. Krothapalli, E. Rajkuperan, F. alvi and L. Lourenco, "Flow field and noise characteristics of a supersonic impinging jet", J. Fluid Mech. vol. 392, pp. 155-181, 1999.

[9] F.S.Alvi and K.G.Iyer, "Mean and Unsteady Flow Field Properties of Supersonic Impinging Jets with Lift Plates", AIAA Paper 99-1829.

[10] S.I. Kim and S.O. Park, "Unsteady Simulation of Supersonic Impinging Jet", AIAA Paper 2003-621, 2003.

[11] Y. Sakakibara and J. Iwamoto, "Oscillation of Impinging jet with generation of acoustic waves", Aeroacoustics, vol. 1(4), pp. 385-402, 2002.

[12] Chang, S.-C., Wang, X.-Y. and Chow, C.-Y., "The Space-Time Conservation Element and Solution Element Method-A New High Resolution and Genuinely Multidimensional Paradigm for Solving Conservation Laws," J. Comp. Phys. vol. 159, pp. 89-136 (1999).

[13] Wang, X.-Y. and Chang S.-C., “ A 2-D Nonsplitting Unstructured Triangular Mesh Euler Solver Based on the Space-Time Conservation Element and Solution Element Method" C.F.D. J. vol. 8, pp. 309-325 (1999).

[14] Loh, C. Y., "On a Nonreflecting Boundary Condition for Hyperbolic Conservation Laws" AIAA Paper 2003-3975 (2003).

[15] Loh, C. Y., Hultgren, L. S. and Chang S.-C., "Computing Waves in Compressible Flow Using the Space-Time Conservation Element Solution Element Method," AIAA J., vol. 39, pp. 794-801 (2001). 
[16] Loh, C. Y. and Zaman, K.B.M.Q., “ Numerical Investigation of Transonic Resonance with a Convergent-Divergent Nozzle", AIAA J., vol. 40, no. 12, pp. 2393-2401 (2002).

[17] Loh, C. Y., Hultgren, L. S., and Jorgenson, P. C. E., "Near Field Screech Noise Computation for an Underexpanded Supersonic Jet by the CE/SE Method", AIAA Paper 2001-2252, (2001). 


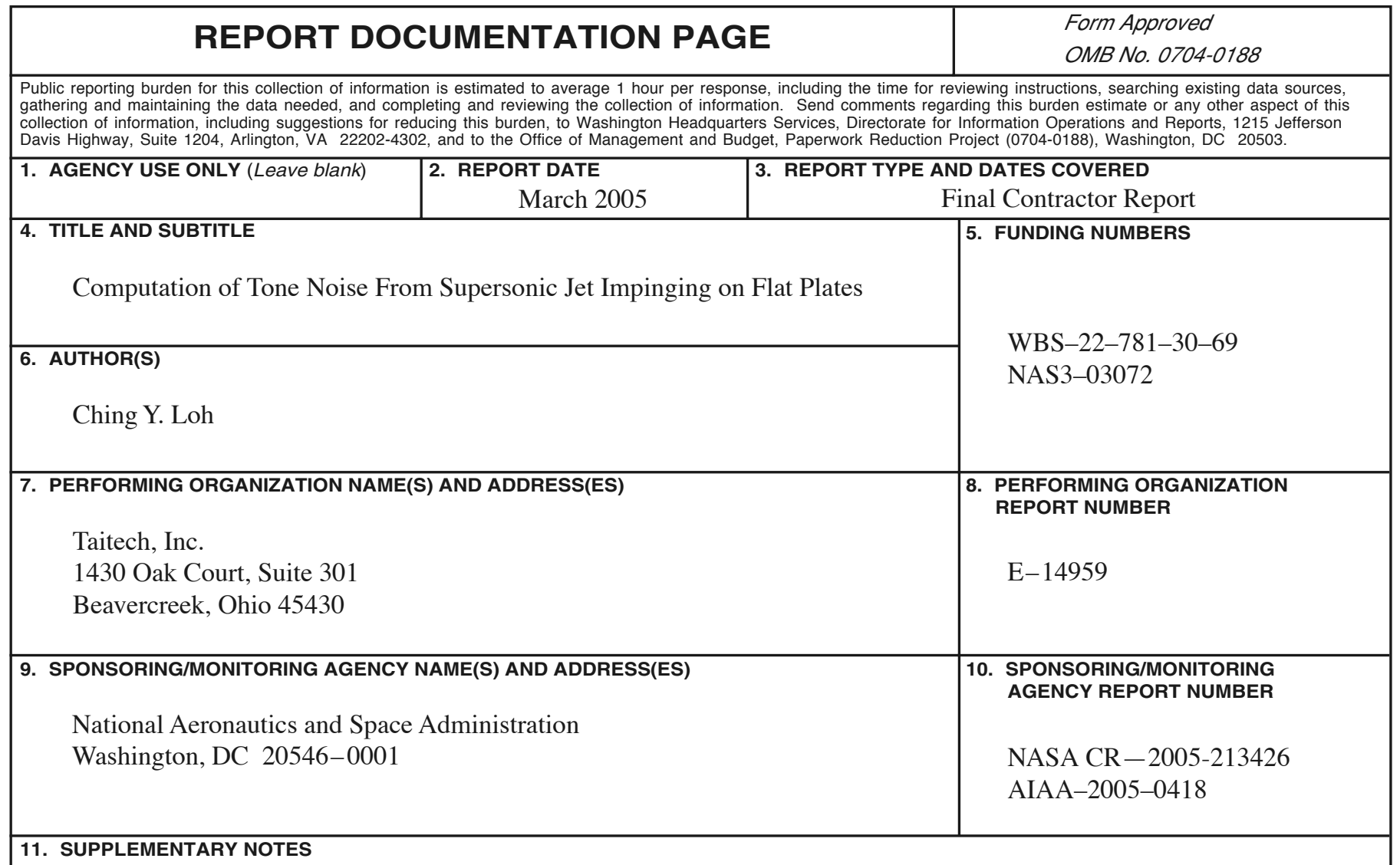

Prepared for the 43rd Aerospace Sciences Meeting and Exhibit sponsored by the American Institute of Aeronautics and Astronautics, Reno, Nevada, January 10-13, 2005. Project Manager, Richard A. Blech, Engine Systems Technology Branch, NASA Glenn Research Center, organization code RTS, 216-433-3981.

12a. DISTRIBUTION/AVAILABILITY STATEMENT

12b. DISTRIBUTION CODE

Unclassified - Unlimited

Subject Categories: 02 and 71

Distribution: Nonstandard

Available electronically at http://gltrs.grc.nasa.gov

This publication is available from the NASA Center for AeroSpace Information, 301-621-0390.

13. ABSTRACT (Maximum 200 words)

A supersonic jet impinging normally on a flat plate has both practical importance and theoretical interests. The physical phenomenon is not fully understood yet. Research concentrates either on the hydrodynamics (e.g., lift loss for STOVL) or on the aeroacoustic loading. In this paper, a finite volume scheme - the space-time conservation element and solution element (CE/SE) method-is employed to numerically study the near-field noise of an underexpanded supersonic jet from a converging nozzle impinging normally on a flat plate. The numerical approach is of the MILES type (monotonically integrated large eddy simulation). The computed results compare favorably with the experimental findings.

\begin{tabular}{|c|c|c|c|}
\hline 14. SUBJECT TERMS & & & $\begin{array}{c}\text { 15. NUMBER OF PAGES } \\
16\end{array}$ \\
\hline NSN 7540-01-280-5500 & & & $\begin{array}{l}\text { Indard Form } 298 \text { (Rev. 2-89) } \\
\text { scribed by ANSI Std. Z39-18 } \\
-102\end{array}$ \\
\hline
\end{tabular}



